Original article

\title{
The effect of repolarization duration on the indices of the pump function of the heart ventricles in animals with different types of activation of the myocardium under ectopic excitation of ventricles
}

\author{
Natalya A. Kibler, Vladimir P. Nyzhny, Dmitry N. Shmakov \\ Komi Science Centre, Ural Branch of Russian Academy of Sciences, Syktyvkar, Russia
}

Received 17 December 2017, Revised 20 April 2018, Accepted 22 June 2018

(C) 2017, Kibler N.A., Nyzhny V.P., Shmakov D.N.

(C) 2017, Russian Open Medical Journal

\begin{abstract}
Background - The aim of the work was to study the influence of myocardial repolarization on the indices of the pump function in animals with different types of the myocardial activation (dog, amphibians) under ectopic excitation of the ventricles.

Material and Methods - Intraventricular blood pressure in animals was measured using a hemodynamic Prucka MacLab 2000 system under basal and apical locations of the stimulating electrode on the ventricles of the heart. The activation-recovery intervals (ARIs) were determined from unipolar myocardial electrograms recorded in the intramural layers of apical and basal parts of the ventricles in dog $(n=16)$ and amphibians (toads Bufo bufo, $n=11$; frogs Rana temporaria, $n=23$ ). Data are presented as median with lower and upper quartiles.

Results - The pacing of the left ventricle apical area in dogs with more prolonged ARIs, as compared with the base, does not change the isovolumic indices of the left ventricle pump function. However, ARIs were longer at the ventricular base - $248(206,260) \mathrm{ms} f o r$ dog's right ventricle and $742(680,929) \mathrm{ms}$ for froggy ventricle, as compared with the apex in the canine right ventricle $-238(219,249) \mathrm{ms}$, and the ventricle in the amphibians $-692(637,860) \mathrm{ms}$. Therefore, pacing of the right ventricle in the apical area in dog and ventricular apex in amphibians leads to a significant decrease of their pump function.

Conclusion - In the animals with successive (amphibians) and flash-successive (dog) types of activation of the myocardium, parameters of the pump function of ventricles were better at pacing of the area with the longest repolarization at the baseline and worse at pacing of the shortest repolarization area.
\end{abstract}

Keywords: pump function, contractility, pressure, repolarization, activation, activation-recovery intervals, ventricle, pacing, dog, amphibians.

Cite as Kibler NA, Nyzhny VP, Shmakov DN. The effect of repolarization duration on the indices of the pump function of the heart ventricles in animals with different types of activation of the myocardium under ectopic excitation of ventricles. Russian Open Medical Journal $2018 ; 7:$ e0305.

Correspondence to Natalya A. Kibler. Address: Laboratory of Cardiac Physiology, Institute of Physiology, Komi Science Center, Urals Division of Russian Academy of Sciences, Pervomayskaya str., 50, Syktyvkar, 167982, Russia. Tel./Fax: +78212240085. E-mail: natanadya@mail.ru.

\section{Introduction}

The investigation of the pump function of the hearts in different classes of vertebrates having different types of myocardial activation is of considerable significance for the comparative electrocardiology. In most investigations [1-6] pump function is studied only in the left ventricle (LV), whereas little is known about RV in the full-blooded vertebrates [7]. Research of the patterns formation of the right ventricle (RV) pump function is relevant for the search of the optimal areas of electrical stimulation, at which disturbances of the hemodynamics will be minimal.

The dependence of the LV pump function on the localization of the focus of ectopic excitation is connected with the ventricular conduction system. In most cases the sequence of activation during pacing of the ventricles is governed by the slow conduction through the normal myocardium, away from the pacing point to the ends of the Purkinje fibers $[1,7-9]$. The amphibians are convenient objects for studying the influence of ectopic excitation on the pump function of the heart, because they have a single ventricle and functional equivalents of the His-Purkinje system [10] that excludes the availability of the interventricular asynchronism of depolarization and contraction of the myocardium in the heart of full-blooded vertebrates.

Since the sequence of activation of ventricular myocardium differs in various systematic groups of animals [11], the question of the comparative-physiological aspect of the cardiac pump function is relevant, for example, in amphibians and predators. At present the influence of the sequence of activation on the cardiac pump function under electrical stimulation is more obvious [2-9], however, little is known, how the repolarization properties of the myocardium affect the indices of the pump function of the ventricles in animals of different classes of vertebrates under ectopic excitation of the ventricles.

Relevant to biomedical sciences is the study of the functional reserve of the heart in animals with low structural organization of 
the myocardium in response to myocardial stress, as is the electrical stimulation. Thus, the aim of the study was to investigate the influence of the duration of repolarization of the myocardium on the heart ventricles pump function indices in animals with different types of the myocardium activation (dog, amphibians) at ectopic excitation of the ventricles.

\section{Material and Methods}

\section{Animals' preparation}

The experiments were perfomed on eleven toads (Bufo bufo), twenty three frogs (Rana temporaria) and sixteen adult male mongrel dogs. The toads (weighing 68-108 g) and frogs (weighing 38-46 g) were anesthetized by placing the animal in the jar with $40 \%$ alcoholic solution for three minutes. After that, chest cavity and pericardium were opened. The temperature of the body in the amphibians was maintained at approximately $18-20^{\circ} \mathrm{C}$.

Dogs, weighing 20-35 kg were anesthetized by zolelil ( $25 \mathrm{mg} / \mathrm{kg}$ body weght, i.m.) with muscle relaxant xylazine ( $3 \mathrm{mg} / \mathrm{kg}$ body weight, i.m.). The study complies with the Guide for the Care and Use of Laboratory Animals published by the US National Institutes of Health (NIH Publication No. 85-23, revised 1996).

During the experiment the dog was injected with a $0.85 \%$ saline to mainlain perfusion of tissues. The animals were rapidly intubated and ventilated artificially through the endotracheal tube. The thorax was opened by a midsternal incision. The pericardium was cut and the heart was suspended in the pericardial cradle. The temperature of the heart was maintained at $38^{\circ} \mathrm{C}$ by the superfusion of the pericardial cradle with temperature-controlled saline.

The stages of the experimental study consisted in measuring the pressure in the LV and RV of the dog and the ventricle in the amphibians, registration of the intramural unipolar electrograms under supraventricular rhythm and successive change of the location of stimulating electrodes in the heart of dogs and amphibians.

\section{Hemodynamic measurements}

Ventricular end-diastolic ventricular pressure (EDVP), maximal systolic ventricular pressures (MSVP), and isovolumic indices (maximal rate of the rise of ventricular pressure $-\mathrm{dP} / \mathrm{dt}_{\max }$, maximal rate of the fall of ventricular pressure $-\mathrm{dP} / \mathrm{dt}_{\min }$ ) were continuously monitored using a Prucka MacLab 2000 system (Ge Medical System, GmbH). For measuring the pressure of the RV in dog and the ventricle in amphibians, a catheter (inside diameter 1 $\mathrm{mm}$ ) filled with heparinized saline was inserted through the free wall into the ventricle cavity. A Swan-Hanz catheter was inserted in the left ventricle through the left femoral artery. Invasive monitoring of the pressure was carried out using the transducers, transforming blood pressure inside the vessels at registering the mechanical changes.

\section{Electrophysiological measurements}

After the catheterization, the plunge needle was inserted into the ventricular myocardium. A set of needle electrodes of diferent lenght having four electrode terminals each was used. General quantity of the electrode terminals was 64 for dogs and 24 for amphibians (Figure 1).
In every intramural lead the activation time (AT), the repolarization time (RT) and the activation-recovery intervals (ARIs) were registered. The latter was used to assess local repolarization duration. The AT, RT and ARIs were determined as $\mathrm{dV} / \mathrm{dt}_{\min }$ during QRS complex, $\mathrm{dV} / \mathrm{dt}_{\max }$ during ST-T complex, and the period between the latter and the former, respectively. The values were determined automatically, inspected by the observer and corrected manually if necessary. In each set of simultaneously recorded electrograms, the beginning of the QRS-complex in the II lead was chosen as the reference timepoint with respect to which ATs and RTs were measured in the given set of electrograms. In order to construct isochronal activation maps, a zero point was determined by the time of the intramural activation breakthrough. Similarly, the zero points on the repolarization maps identify the earliest repolarization of the myocardium.

\section{Pacing protocol}

In both animals epicardial pacing of the ventricles was performed by laboratory electrocardiostimulator EKSN-04M (Axion Ltd, Russia). Supraventricular rhythm was used, in order to avoid high variability of the heart rate, which was observed under the sinus rhythm. In animals the right atrium and the ventricular epicardium were stimulated by rectangular impulses (amplitude $3.5 \mathrm{~V}$; duration $-1 \mathrm{~ms}$ ) with a forced heart rate of 50 beats per minute in amphibians and 150 beats per minute in dog.

Epicardial electrical pacing of the base and apex of the LV and RV (Figure 2a) was performed to change the sequence of activation of the myocardium. In amphibians a pacing electrode was placed in the right atrium, the base and the apex of the ventricle (Figure $2 \mathrm{~b}$ ).

Electrograms were recorded later than 100 cardiac cycles in dog and 20 cycles in amphibians after the change of rhythmic regime. The duration of each series of the impulse was 5 minutes in dog and 0.5 minutes in amphibians.

\section{Statistical analysis}

A statistical study was performed using nonparametric Wilcoxon test for paired comparisons and Fridman test followed by the Newman-Keuls or Dunnet's tests for multiple comparisons. The differences were considered significant at $\mathrm{P}<0.05$.

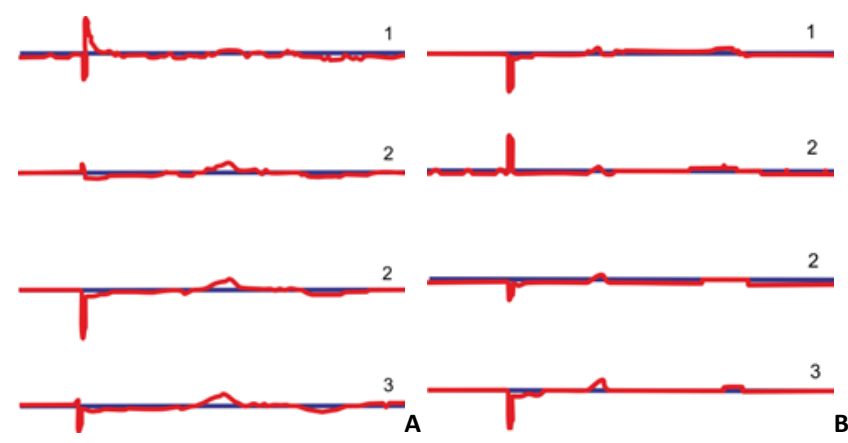

Figure 1. Representative electrograms from the different areas of base $(A)$ and apex (B) of the ventricle of heart in the frog $R$. temporaria under atrial pacing. 1 -subendocardium, 2 -midmyocardium, 3 -subepicardium. 
Table 1. Repolarization durations measured as ARIs throughout the ventricular subepicardium at atrial pacing in dog and frog $R$. temporaria

\begin{tabular}{|c|c|c|c|c|c|c|}
\hline \multirow[t]{2}{*}{ Parameter } & \multicolumn{4}{|c|}{ Dog } & \multicolumn{2}{|c|}{ R. temporaria } \\
\hline & LV apex & LV base & RV apex & RV base & Ventrical apex & Ventrical base \\
\hline ARIs, ms & $255(199,281)$ & $235(232,257), P=0.049$ & $238(219,249)$ & $248(206,260), P=0.010$ & $692(637,860)$ & $742(680,929), P=0.025$ \\
\hline
\end{tabular}

Data are presented as median with lower and upper quartiles - Me (LQ, UQ). P-level for differences with apex of the same ventricle.

$A R I$, activation-recovery interval; LV, left ventricular; RV, right ventricular.

Table 2. Hemodynamic variables at atrial and ventricular pacing in amphibians

\begin{tabular}{|c|c|c|c|c|c|c|}
\hline \multirow[t]{2}{*}{ Parameters } & \multicolumn{3}{|c|}{ R. temporaria } & \multicolumn{3}{|c|}{ B. bufo } \\
\hline & Atrial pacing & $\begin{array}{l}\text { Pacing of } \\
\text { ventricular base }\end{array}$ & $\begin{array}{l}\text { Pacing of ventricular } \\
\text { apex }\end{array}$ & Atrial pacing & $\begin{array}{l}\text { Pacing of } \\
\text { ventricular base }\end{array}$ & $\begin{array}{l}\text { Pacing of } \\
\text { ventricular apex }\end{array}$ \\
\hline \multirow[t]{2}{*}{ MSPV, mmHg } & $9(5,12)$ & $6(3,8)$ & $5(3,7)$ & $25(22,28)$ & $18(15,24)$ & $17(14,23)$ \\
\hline & & $P_{1}=0.050$ & $P_{1}=0.035, P_{2}=0.179$ & & $P_{1}=0.045$ & $P_{1}=0.028, P_{2}=0.052$ \\
\hline \multirow[t]{2}{*}{$\mathrm{dP} / \mathrm{dt}_{\max }, \mathrm{mmHg} / \mathrm{s}$} & $19(14,25)$ & $16(11,21)$ & $13(10,20)$ & $142(135,173)$ & $125(101,157)$ & $118(88,128)$ \\
\hline & & $P_{1}=0.042$ & $P_{1}=0.027, P_{2}=0.042$ & & $P_{1}=0.028$ & $P_{1}=0.017, P_{2}=0.023$ \\
\hline \multirow[t]{2}{*}{$\mathrm{dP} / \mathrm{dt}_{\min }, \mathrm{mmHg} / \mathrm{s}$} & $36(23,44)$ & $30(17,32)$ & $25(14,30)$ & $123(111,155)$ & $88(75,113)$ & $77(70,97)$ \\
\hline & & $P_{1}=0.043$ & $P_{1}=0.042, P_{2}=0.021$ & & $P_{1}=0.032$ & $P_{1}=0.010, P_{2}=0.029$ \\
\hline \multirow[t]{2}{*}{ EDPV, $\mathrm{mmHg}$} & $2(1,2)$ & $1(0,2)$ & $1(0,2)$ & $2(0,2)$ & $2(0,2)$ & $1(0,2)$ \\
\hline & & $P_{1}=0.960$ & $P_{1}=0.570, P_{2}=0.131$ & & $P_{1}=0.240$ & $P_{1}=0.078, P_{2}=0.089$ \\
\hline
\end{tabular}

Data are presented as median with lower and upper quartiles - Me (LQ, UQ). $P_{1}$-level for differences with atrial pacing; $P_{2}$-level (apex vs. base).

MSPV, maximal systolic ventricular pressure; $d P / d t_{\max }$ and $d P / d t_{\min }$, the maximal rate of the rise and fall of ventricular pressure; EDPV, end-diastolic ventricular pressure.
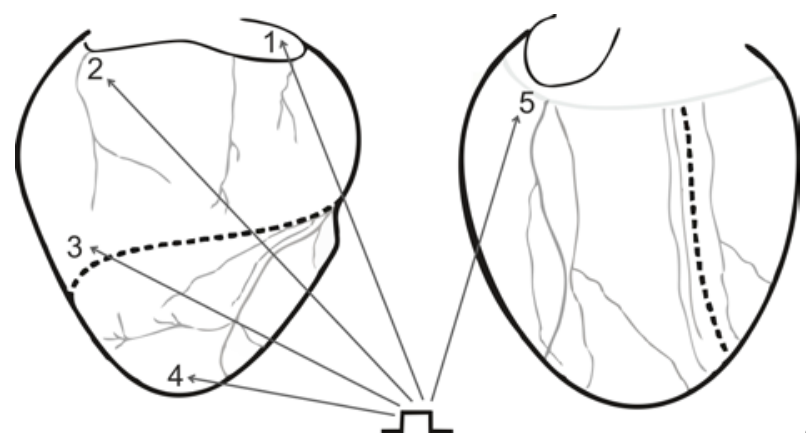

A

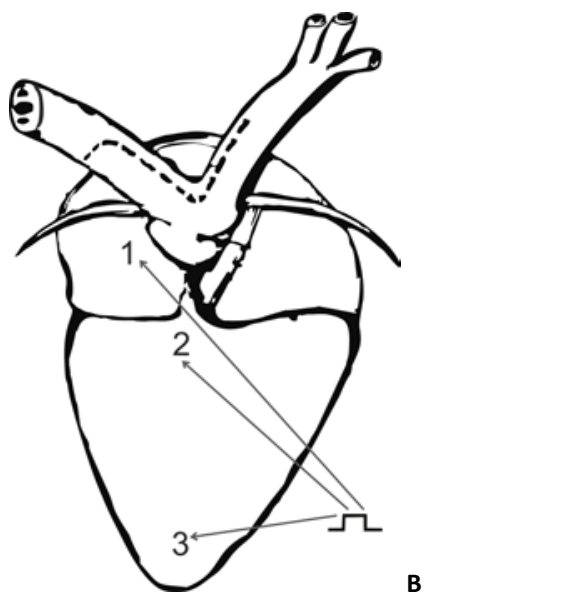

Figure 2. Layout of stimulating electrodes on the ventricular epicardium and right atrium in the heart $\operatorname{dog}$ (A: 1- right atrium; 2- base of right ventricle; 3- apex of right ventricle; 4 - apex of left ventricle; 5 - base of left ventricle) and frog (B: 1- right atrium; 2- base of ventricle; 3- apex of ventricle).

\section{Results}

The apical-basal distribution of the repolarization durations of the subepicardium of the ventricles in amphybians and dogs under supraventricular rhythm

In amphibians ( $R$. temporaria) repolarization durations decreased $(P=0.025)$ from the basal area of the ventricle to the apex (Table 1).

At supraventricular excitation in the LV in dogs ARIs were significantly longer at the apex and shorter in the basal area $(P=0.049)$, whereas the reverse was observed in the RV $(P=0.010)$ (Table 1).

The parameters of the pump function of the heart at ventricular pacing in amphibians

The maximal systolic pressure in the ventricle of the amphibians (B. bufo, $R$. temporaria) was reduced $(\mathrm{P}<0.05)$, as compared with supraventricular rhythm (Table 2). This stimulation regime reduced $(P<0.05)$ the maximum rate of the ventricular pressure rise $\mathrm{dP} / \mathrm{dt}_{\max }$ and the maximum rate of the ventricular pressure fall $\mathrm{dP} / \mathrm{dt}_{\min }$ in toad and frog, as compared to supraventricular rhythm. However, under apical pacing the maximal systolic pressure, $\mathrm{dP} / \mathrm{dt}_{\max }$ and $\mathrm{dP} / \mathrm{dt}_{\min }$ in the ventricle were reduced to a greater degree $(P<0.01)$, as compared to supraventricular rhythm and basal pacing (Table 2 ). The preload in the ventricle in amphibians decreased significantly at pacing the ventricular apex (Table 2).

Thus, the stimulation of the ventricular apex in amphibians (B. bufo, R. temporaria) significantly worsened all parameters of systolic (MVSP, $\left.\mathrm{dP} / \mathrm{dt}_{\max }\right)$ and diastolic functions $\left(\mathrm{dP} / \mathrm{dt}_{\min }\right)$. 
Table 3. Hemodynamic variables at atrial and ventricular pacing in dog

\begin{tabular}{|c|c|c|c|c|c|}
\hline \multirow[t]{2}{*}{ Parameters } & \multirow[t]{2}{*}{ Atrial pacing } & \multicolumn{2}{|c|}{ RV pacing } & \multicolumn{2}{|c|}{ LV pacing } \\
\hline & & Apex & Base & Apex & Base \\
\hline \multirow[t]{2}{*}{ MSPLV, $\mathrm{mm} \mathrm{Hg}$} & $111(106,129)$ & $96(92,101)$ & $100(94,113)$ & $107(104,116)$ & $105(98,116)$ \\
\hline & & $P_{1}=0.050$ & $P_{1}=0.050, P_{2}=0.153$ & $P_{1}=0.071$ & $P_{1}=0.050, P_{2}=0.050$ \\
\hline \multirow[t]{2}{*}{$\mathrm{dP} / \mathrm{dt}_{\max } \mathrm{LV}, \mathrm{mmHg} / \mathrm{s}$} & $1296(1080,1696)$ & $1104(984,1280)$ & $1152(960,1536)$ & $1440(1116,1596)$ & $1242(1126,1368)$ \\
\hline & & $P_{1}=0.032$ & $P_{1}=0.045, P_{2}=0.187$ & $P_{1}=0.054$ & $P_{1}=0.752, P_{2}=0.022$ \\
\hline \multirow[t]{2}{*}{$\mathrm{dP} / \mathrm{dt}_{\min } \mathrm{LV}, \mathrm{mmHg} / \mathrm{s}$} & $-1200(-995,-1583)$ & $-851(-683,-910)$ & $-909(-825,-959)$ & $-1125(-1011,-1565)$ & $-967(-844,-1164)$ \\
\hline & & $P_{1}=0.020$ & $P_{1}=0.032, P_{2}=0.965$ & $P_{1}=0.092$ & $P_{1}=0.046, P_{2}=0.129$ \\
\hline \multirow[t]{2}{*}{ EDPLV, $\mathrm{mmHg}$} & $9(4,17)$ & $7(5,13)$ & $13(3,16)$ & $9(2,14)$ & $9(4,14)$ \\
\hline & & $P_{1}=0.061$ & $P_{1}=0.067, P_{2}=0.067$ & $P_{1}=1.000$ & $P_{1}=1.000, P_{2}=1.000$ \\
\hline \multirow[t]{2}{*}{ MSPRV, mmHg } & $18(18,23)$ & $14(14,20)$ & $16(14,21)$ & $15(14,20)$ & $16(15,23)$ \\
\hline & & $P_{1}=0.050$ & $P_{1}=0.088, P_{2}=0.092$ & $P_{1}=0.050$ & $P_{1}=0.061, P_{2}=0.986$ \\
\hline \multirow[t]{2}{*}{$\mathrm{dP} / \mathrm{dt}_{\max } \mathrm{RV}, \mathrm{mmHg} / \mathrm{s}$} & $264(196,381)$ & $230(153,240)$ & $265(228,306)$ & $286(215,291)$ & $280(240,337)$ \\
\hline & & $P_{1}=0.050$ & $P_{1}=0.923, P_{2}=0.046$ & $P_{1}=0.073$ & $P_{1}=0.068, P_{2}=0.803$ \\
\hline \multirow[t]{2}{*}{$\mathrm{dP} / \mathrm{dt}_{\min } \mathrm{RV}, \mathrm{mmHg} / \mathrm{s}$} & $-239(-171,-345)$ & $-136(-124,-182)$ & $-230(-166,-291)$ & $-204(-94,-289)$ & $-218(-117,-320)$ \\
\hline & & $P_{1}=0.052$ & $P_{1}=0.762, P_{2}=0.064$ & $P_{1}=0.075$ & $P_{1}=0.089, P_{2}=0.257$ \\
\hline \multirow[t]{2}{*}{ EDPRV, $\mathrm{mmHg}$} & $0(0,1)$ & $1(0,4)$ & $2(1,5)$ & $2(1,3)$ & $1(0,3)$ \\
\hline & & $P_{1}=0.092$ & $P_{1}=0.083, P_{2}=0.256$ & $P_{1}=0.085$ & $P_{1}=0.099, P_{2}=0.871$ \\
\hline
\end{tabular}

Data are presented as median with lower and upper quartiles - Me (LQ, UQ). $P_{1}$-level for differences with atrial pacing; $P_{2}$-level (apex vs. base).

LV, left ventricular; RV, right ventricular; MSPLV and MSPRV, maximal systolic LV and RV pressure; $d P / d t_{\max }$ and dP/dt $\mathrm{min}_{\mathrm{m}}$, the maximal rate of the rise and fall of ventricular pressure; EDPLV and MSPRV, end diastolic LV and RV pressure.

The parameters of the pump function of the $L V$ and $R V$ of the heart at ventricular pacing in dog

Pacing of the LV base and apex. Under the LV basal pacing the maximal LV systolic pressure and LV $\mathrm{dP} / \mathrm{dt}_{\max }$ were largely decreased $(P<0.05)$, as compared to supraventricular rhythm. Besides, the systolic function (maximal LV systolic pressure and LV $\left.\mathrm{dP} / \mathrm{dt}_{\max }\right)$ was reduced $(\mathrm{P}<0.05)$, as compared to LV apical pacing. Maximal RV systolic pressure, maximal rate of the rise of RV pressure, maximal rate of the fall of RV pressure were reduced insignificantly, as compared to supraventricular rhythm. Left ventricular apex pacing did not change maximal LV systolic pressure, $\mathrm{LV} \mathrm{dP} / \mathrm{dt}_{\max }$ and $\mathrm{LV} \mathrm{dP} / \mathrm{dt}_{\min }$ in the LV as compared to supraventricular rhythm, but maximal RV systolic pressure was reduced $(\mathrm{P}<0.05)$ (Table 3$)$.

\section{Pacing of the RV base and apex}

The maximal LV systolic pressure and LV $\mathrm{dP} / \mathrm{dt}_{\min }$ were reduced $(P<0.05)$ under the $R V$ basal pacing, as compared to supraventricular rhythm, at that the maximal rate of the rise of RV pressure increased $(P<0.05)$ as compared to RV apical pacing (Table 3). RV apex pacing significantly reduced $(\mathrm{P}<0.05)$ all indices of systolic (maximal systolic pressure and $\mathrm{dP} / \mathrm{dt}_{\max }$ ) and diastolic function $\left(\mathrm{dP} / \mathrm{dt}_{\mathrm{min}}\right)$ in the LV and RV (except for $\mathrm{dP} / \mathrm{dt}_{\text {min }}$ ), as compared to supraventricular rhythm and electrical stimulation of other areas of the ventricles. Generally, ventricular pacing did not affect the preload (LV and RV end-diastolic pressure) (Table 3).

Thus, pacing of the right ventricular apex reduced RV function more than electrical stimulation of the RV basal area, whereas the reverse was observed in the LV.

\section{Discussion}

The present investigation, perfomed in the hearts of dog and amphibians has shown that: 1) pacing of the apical area of the ventricle considerably reduces the parameters of the cardiac hemodynamics more in animals with successive (toad and frog) type of activation of the myocardium; 2) in dog the indices of the pump function of the LV were better at pacing of the LV apex, while in the RV conversely - at pacing of the RV base; 3 ) in animals with successive (frog) and flash-successive (dog) types of activation of the myocardium, the parameters of the pump function of ventricles decreased to a lesser extent at stimulation of the area with prolonged repolarization in the initial state.

The ventricular pump function of the heart at electrical stimulation in animals with successive (toad and frog) and flashsuccessive (dog) types of activation of the myocardium

Ventricular pacing reduces the pump function independent of pre- and afterload in animals with successive (toad and frog) and flash-successive (dog) types of activation of the myocardium. The ectopic excitation of the RV apical area more expresses the inotropic effect on the pump function in both ventricles in dogs. At that, parameters of cardiac hemodynamics were significantly lower at pacing of the RV apex that corresponds to the data of other authors $[6,15-20]$. In amphibians the indices of the pump function of the heart decreased at ventricular pacing (base and apex). However, the pump function of the heart suffers more when pacing the apical area of the ventricle, as compared to supraventricular rhythm and basal pacing.

Previously, it was shown that at pacing of the middle part of the LV epicardium [21] and RV pacing [16, 22-24] the systolic pressure and $\mathrm{dP} / \mathrm{dt}_{\max }$ are reduced, as compared to supraventricular rhythm. Nevertheless, one of the groups has shown better isovolumic indices at LV apex pacing 5 and pacing of the middle ventral part of LV [21], as compared to LV base pacing. 
Table 4. The correlating relation between contractility and relaxation indices of the ventricles of canine heart under supraventricular rhythm and ectopic excitation of the ventricles $(n=11)$

\begin{tabular}{|c|c|c|c|c|c|}
\hline Pairs of variables & Supraventricular rhythm & Pacing of RV apex & Pacing of RV base & Pacing of LV apex & Pacing of $L V$ base \\
\hline $\mathrm{dP} / \mathrm{dt}_{\max }-\mathrm{dP} / \mathrm{dt}_{\min }(\mathrm{LV})$ & $r=0.92, P=0.001$ & $r=0.79, P=0.013$ & $r=0.84, P=0.011$ & $r=0.76, P=0.010$ & $r=0.75, P=0.013$ \\
\hline $\mathrm{dP} / \mathrm{dt}_{\min }-\mathrm{dP} / \mathrm{dt}_{\max }(\mathrm{RV})$ & $r=0.94, P=0.001$ & $r=0.79, P=0.048$ & $r=0.77, P=0.046$ & $r=0.71, P=0.048$ & $r=0.71, P=0.047$ \\
\hline
\end{tabular}

$\mathrm{LV}$, left ventricular; $\mathrm{RV}$, right ventricular; $\mathrm{dP} / \mathrm{dt}_{\max }$ and $\mathrm{dP} / \mathrm{dt}_{\min }$, the maximal rate of the rise and fall of ventricular pressure.

Because ventricular pacing increases the degree of inhomogeneity in contraction and relaxation, it is not surprising that ventricular pacing also impairs ventricular relaxation $[5,6,25]$. Many studies report that only LV pacing leads to the increase of the duration of contraction and thus, reduces velocity of isovolumic relaxation of the ventricle $[18,26]$. In the present study we found out that ventricular pacing in dogs and amphibians decreases isovolumic indices ( $\mathrm{dP} / \mathrm{dt}_{\max }$ and $\left.\mathrm{dP} / \mathrm{dt}_{\min }\right)$.

Thus, pacing of various areas (apex and base) has similar effect

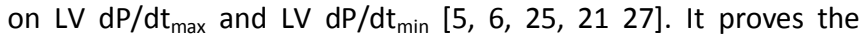
presence of positive correlation between $\mathrm{dP} / \mathrm{dt}_{\max }$ and $\mathrm{dP} / \mathrm{dt}_{\min }$ in the canine LV and RV (Table 4) and the ventricle in the amphibians (basal pacing $r=0.66, P=0.048$; apical pacing $r=0.91, P=0.001$ ). This relationship between contractility and relaxation parameters can be explained as follows. At the increase of the contractility the greater stroke volume reduces end-systolic volume. Under the reduced end-systolic volume, as a result of increase of the velocity of dissociation of the $\mathrm{Ca}^{2+}-\mathrm{TnC}$ complex $\left(\mathrm{Ca}^{2+}\right.$ ions troponin Crelated) [28], the maximal rate of the rise in ventricular pressure increased, and, accordingly, the relaxation process improved [29].

As a result, pacing of RV apex in dogs worsens the RV function, as compared with its basal pacing, and vice versa - the LV function is consistently better at pacing of the LV apex than at pacing of the LV base. In amphibians pacing of the ventricular apical area leads to a significant decrease of its pump function.

Differences of contractile characteristics at change of the ectopic focus of activation within the ventricles in dogs and amphibians are, possibly, connected with the mechanism of regulation of contractions of the myocardium at the cellular level. This mechanism involves the change in the duration of local repolarization and homeostasis of cardiomyocytes [30].

The effects of the repolarization durations on the indices of the pump function of ventricles in dogs and amphibians

The ARIs duration corresponding to the action potential durations [31,32] at ventricular pacing is unlikely to have changed in different areas of the ventricles in homothermic and poikilothermic animals. In earlier studies [12-14] it was shown that in dogs at supraventricular rhythm ARIs were longer in the apical LV area, as compared to its base. While, for the RV the opposite is characteristic - larger ARIs at the base of the ventricle, as compared to the apical area.

In this study it was found, that the duration of repolarization in the RV basal area was longer in dogs and the LV of amphibians, while LV in dogs is characterized by longer ARIs in the apical area.

Mathematical models of heterogeneous myocardium $[28,30]$ show that excitation wave goes from "fast" to "slow" virtual cardiac muscle [30, 33]. Under the similar amplitude of contraction: the "fast" muscle reached peak force earlier and relaxed faster, than the "slow" one. This difference is the result of the change in the velocity of $\mathrm{Ca}^{2+}$ release from the sarcoplasmatic reticulum that reflected the duration of $\mathrm{Ca}^{2+}$ transition in the muscles: faster and less prolonged contraction in "fast" muscle was accompanied by more rapid and short $\mathrm{Ca}^{2+}$ transition. Besides, relative to "slow" muscle $\mathrm{Ca}^{2+}$ transition to a faster virtual muscle has a rapid contraction and shorter duration of action potential. At the same time, pacing of the "fast" muscle reduces the contractility of the myocardium, but pacing of the "slow" one changes insignificantly [30, 34-36]. Thus, we can assume that the electrical pacing of the ventricular area with longer ARIs does not change the contractility, while pacing of the ventricular area with shorter ARIs leads to the reduction of the pump function of the heart.

Our results showed that in dogs pacing of the LV apical area with more prolonged ARIs as compared to the basal part did not change the isovolumic indices of the LV pump function. However, in the RV in dogs and the ventricle in amphibians ARIs were longer at the ventricular base, as compared to the apex. Therefore, pacing of the RV apical area in dogs and ventricular apex in amphibians leads to a significant decrease of their pump function.

\section{Conclusion}

In animals with successive (toad) and flash-successive (dog) types of activation of the myocardium, parameters of the pump function of ventricles were better at pacing of the area with the longest repolarization duration in the initial period and worse at pacing of the area with the shortened repolarization duration.

\section{Limitations}

In our study the frogs were anaesthetized by $40 \%$ ethanol. In experimental works in amphibia authors used for anaesthesia different drugs: methanesulfonate (MS-222) [37, 38], ether [39, 40] and urethane [41]. So further experiments are necessary to compare effects of these drugs on the amphibian cardiovascular system.

The extrapolation of the experimental results of the present investigation obtained from the canine hearts to the clinical settings could be done only with caution taking into account potential interspecies differences. On the other hand, the findings of the electrophysiological studies reviewed by Nerbonne and Kass [42] suggested that the properties of cardiac ion channels and action potential variables are similar in humans and other large mammals including dogs, thus supporting the validity of such an extrapolation. Another limitation concerns the fact that the animals used in the experiments were healthy. The underlying heart diseases characteristic to patients with indications for cardiac resynchronization therapy could have made a contribution to either the electrophysiological or haemodynamic effects of stimulation. Furthermore, only the acute responses to cardiac pacing were examined here while the long-term electrical and mechanical remodelling could modify the suggestions of the present investigation. Finally, the measurements of repolarization durations were done by the ARIs in the unipolar electrograms. This method was chosen because of its applicability for the 
measurements in in vivo settings, specifically in the intramural ventricular layers. Although this approach has been validated several times $[31,32,43,44]$ it should be used cautiously due to its indirect nature.

\section{Ethical approval}

All applicable international, national, and institutional guidelines for the care and use of animals were followed. According to independent local bioethics committee of Komi Science Center (Urals Division of Russian Academy of Sciences RAS, Syktyvkar, Russia) all procedures performed in studies involving animals were in accordance with the ethical standards of the institution or practice at which the studies were conducted.

\section{Funding}

The study was supported by the Program for Fundamental Research of RAS (2013-2020), project № AAAA-A17-117012310154-6.

\section{Conflict of Interest}

The authors declare that they have no conflict of interest.

\section{References}

1. Lister JW, Klotz DH, Jomain SL, Stuckey JH, Hoffman B. Effect of pacemaker site on cardiac output and ventricular activation in dogs with complete heart block. Am J Cardiol 1964; 14: 494-503. https://dx.doi.org/10.1016/0002-9149(64)90033-5.

2. Park RC, Little WC, O'Rourke RA. Effect of alteration of left ventricular activation sequence on the left ventricular end-systolic pressurevolume relation in closed-chest dogs. Circ Res 1985; 57: 706-717. https://dx.doi.org/10.1161/01.RES.57.5.706.

3. Burkhoff D, Oikawa RY, Sagawa K. Influence of pacing site on left ventricular contraction. Am J Physiol Heart Circ Physiol 1986; 251: 428435. https://dx.doi.org/10.1152/ajpheart.1986.251.2.H428.

4. Rosenqvist $M$, Bergfeldt $L$, Haga $Y$, Rydén $L$, Öwall $A$. The effect of ventricular activation sequence on cardiac performance during pacing. PACE 1996; 19: 1279-1287. https://dx.doi.org/10.1111/i.15408159.1996.tb04205.x.

5. Prinzen FW, Oosterhout MFM Van, Vanagt WYR, Storm C, Reneman RS. Optimization of ventricular function by improving the activation sequence during ventricular pacing. PACE 1998; 21: 2256-2260. https://dx.doi.org/10.1111/j.1540-8159.1998.tb01163.x.

6. Peschar $M$, de Swart $H$, Michels KJ, Reneman RS, Prinzen FW. Left ventricular septal and apex pacing for optimal pump function in canine hearts. J Am Coll Cardiol 2003; 41: 1218-1226. https://dx.doi.org/10.1016/S0735-1097(03)00091-3.

7. Prinzen FW, Peschar M. Relation Between the Pacing Induced Sequence of Activation and Left Ventricular Pump Function in Animals. PACE 2002; 25: 484-498. https://dx.doi.org/10.1046/j.14609592.2002.00484.x.

8. Spach MS, Barr RC. Ventricular intramuscular and epicardial potential distributions during ventricular activation and repolarization in the intact dog. Circ Res 1975; 37: 243-257. https://dx.doi.org/10.1161/01.RES.37.2.243.

9. Vassallo JA, Cassidy DM, Miller JM, Buxton AE, Marchlinski FE, Josephson $M E$. Left ventricular endocardial activation during right ventricular pacing: effect of underlying heart disease. J Am Coll Cardiol 1986; 7: 1228-1233. https://dx.doi.org/10.1016/S0735-1097(86)80140-1.

10. Sedmera D, Reckova $M$, DeAlmeida A, Sedmerova $M$, Biermann $M$. Functional and morphological evidence for ventricular conduction system in zebrafish and Xenopus heart. Am J Physiol Heart Circ Physiol 2003; 284 : 1152-1160. https://dx.doi.org/10.1152/ajpheart.00870.2002.

11. Roshchevsky MP, Shmakov DN. Excitation of the Heart. Moscow: Nauka, 2003; 143 p. Russian.
12. Tsvetkova AS, Kibler NA, Azarov YE, Nuzhny VP, Shmakov DN. Repolarization of canine ventricular myocardium under the supraventricular rhythm. Ross Fiziol Zh Im I M Sechenova 2008; 94: 523-531. Russian. https://www.ncbi.nlm.nih.gov/pubmed/18669357.

13. Tsvetkova AS, Nuzhny VP, Kibler NA, Azarov YE, Shmakov DN. Repolarization of canine ventricular myocardium under the atrioventricular pacing of heart. Bull Exp Biol Med 2008; 146: 131-134. Russian. https://dx.doi.org/10.1007/s10517-008-0239-7.

14. Tsvetkova AS, Kibler NA, Azarov JE, Shmakov DN, Nyzhniy VP. Acute effects of pacing site on repolarization and haemodynamics of the canine ventricles. Europace 2011; 11: 889-896. https://dx.doi.org/10.1093/europace/eur053.

15. Gilmore JP, Sarnoff SJ, Mitchell JH. Synchronicity of ventricular contraction: Observations comparing hæmodynamic effects of atrial and ventricular pacing. Br Heart J 1963; 25: 299-307. https://dx.doi.org/10.1136/hrt.25.3.299.

16. Grover M, Glantz SA. Endocardial pacing site affects left ventricular end-diastolic volume and performance in the intact anesthetized dog. Circ Res 1983; 53: 72-85. https://dx.doi.org/10.1161/01.RES.53.1.72.

17. Prinzen FW, Augustijn $\mathrm{CH}$, Arts $\mathrm{T}$, Allessie MA, Reneman RS. Redistribution of myocardial fiber strain and blood flow by asynchronous activation. Am J Physiol 1990; 259: 300-308. https://dx.doi.org/10.1152/ajpheart.1990.259.2.H300.

18. Hay I, Melenovsky V, Fetics BJ. Short-term effects of right-left heart sequential cardiac resynchronization in patients with heart failure, chronic atrial fibrillation, and atrioventricular nodal block. Circulation 2004; 110: 3404-3410. https://dx.doi.org/10.1161/01.CIR.0000148177.82319.C7.

19. Gassis SA, DeLurgio DB, Leon AR. Progress in cardiovascular disease: technical considerations in cardiac resynchronization therapy. Progress in Cardiovascular Diseases 2006; 48: 239-255. https://dx.doi.org/10.1016/j.pcad.2006.01.001.

20. Kibler NA, Kharin SN, Tsvetkova AS, Azarov YE, Shmakov DN. Effect of ectopic excitation on pump function of the hen and dog right heart ventricle. Zn Evol Biokhim Fiziol 2009; 45: 92-96. Russian. https://dx.doi.org/10.1134/S0022093009010104.

21. Ashikaga $\mathrm{H}$, Omens $\mathrm{JH}$, Ingels NB. Transmural mechanics at left ventricular epicardial pacing site. Am J Physiol Heart Circ Physiol 2004; 286: 2401-2407. https://dx.doi.org/10.1152/ajpheart.01013.2003.

22. Truex RC, Copenhaver WM. Histology of the moderator band in man and other mammals with special reference to the conduction system. Am J Anat 1947; 80: 173-200. https://www.ncbi.nlm.nih.gov/pubmed/20286213.

23. Hoffman BF, Cranefield PF, Stuckley JH. Direct measurement of conduction velocity in situ specialized conduction system of mammalian heart. Proc Soc Exp Biol Med 1959; 102: 55-57. https://www.ncbi.nlm.nih.gov/pubmed/14402387

24. Heyndrickx GR, Vilane J-P, Khight DR, Vatner SF. Effects of altered site of electrical activation on myocardial performance during inotropic stimulation. Circulation 1985; 71: 1010-1016. https://dx.doi.org/10.1161/01.CIR.71.5.1010.

25. Simantirakis EN, Vardakis KE, Kochiadakis GE, Manios EG, Igoumenidis NE. Left Ventricular Mechanics During Right Ventricular Apical or Left Ventricular-Based Pacing in Patients With Chronic Atrial Fibrillation After Atrioventricular Junction Ablation. J Am Coll Cardiol 2004; 43: 1013-1018. https://dx.doi.org/10.1016/j.jacc.2003.10.038.

26. Spragg D, Kass DA. Pathobiology of left ventricular dyssynchrony and resynchronization. Progress in Cardiovascular Diseases 2006; 49: 2641. https://dx.doi.org/10.1016/j.pcad.2006.05.001.

27. Henning RJ, Levy MN. Effects of autonomic nerve stimulation, asynchrony, and load on dP/dt max and on dP/dt min. Am J Physiol 1991; 260: 12901298. https://dx.doi.org/10.1152/ajpheart.1991.260.4.H1290.

28. Solovyova O, Vikulova N, Katsnelson LB, Markhasin VS. Mechanical interaction of heterogeneous cardiac muscle gments in silico: effects on $\mathrm{Ca}^{2+}$ handling and action potential. Intern J Bifurcation Chaos 2003; 13: 3757-3782. https://dx.doi.org/10.1016/S0079-6107(03)00017-8. 
29. Brutsaert DL, Sys SU. Relaxation and diastole of the heart. Physiol Rev 1989; 69: 1228-1301. https://dx.doi.org/10.1152/physrev.1989.69.4.1228

30. Solovyova O, Katsnelson LB, Konovalov P, Lookin O, Moskvin AS, Protsenko YL, Vikulova N, Kohl P, Markhasin VS. Activation sequence as a key factor in spatio-temporal optimization of myocardial function. Philos Transact A Math Phys Eng Sci 2006; 364: 1367-1383. https://dx.doi.org/10.1098/rsta.2006.1777.

31. Millar CK, Kralios FA, Lux RL. Correlation between refractory periods and activation-recovery intervals from electrogramms: effect of rate and adrenergic interventions. Circulation 1985; 72: 1372-1379. https://dx.doi.org/10.1161/01.CIR.72.6.1372.

32. Haws CW, Lux RL. Correlation between in vivo transmembrane action potential durations and activation-recovery intervals from electrograms. Effects of interventions that alter repolarization time. Circulation 1990; 81: 281-288. https://dx.doi.org/10.1161/01.CIR.81.1.281.

33. Solovyova O, Konovalov P, Vikulova N, Katsnelson LB, Markhasin VS. Research of electromechanical and machano-electrical coupling in myocardium under the mathematical model. Ross Fiziol Zh Im I M Sechenova 2007; 93: 945-968. Russian. https://www.ncbi.nlm.nih.gov/pubmed/18030795.

34. Cordeiro JM, Greene L, Heilmann C, Antzelevitch D. Transmural heterogeneity of calcium activity and mechanical function in the canine left ventricle. Am J Physiol Heart Circ Physiol 2004; 286: 14711479. https://dx.doi.org/10.1152/ajpheart.00748.2003.

35. Kondo RP, Dederko DA, Teutsch C, Chrast J, Catalucci D. Comparison of contraction and calcium handling between right and left ventricular myocytes from adult mouse heart: a role for repolarization waveform. J Physiol 2006; 571: 131-146. https://dx.doi.org/10.1113/jphysiol.2005.101428

36. Ashikaga H, Coppola BA, Hopenfeld B, Leifer ES, McVeigh ER. Transmural dispersion of myofiber mechanics implications for electrical heterogeneity in vivo. Am J Physiol Heart Circ Physiol 2007; 49: 909-916. https://dx.doi.org/10.1016/j.jacc.2006.07.074.

37. Warburton J, Fritsche R. Blood pressure control in a larval amphibian, Xenopus laevic. J Exp Biol 2000; 203: 2047-2052. https://www.ncbi.nlm.nih.gov/pubmed/10851121.

38. Cakir Y, Strauch SM. Tricaine (MS-222) is a safe anesthetic compound compared to benzocaine and pentobarbital to induce anesthesia in leopard frogs (Rana pipiens). Pharmacol Reports 2005; 57: 467-474. https://www.ncbi.nlm.nih.gov/pubmed/16129913.

39. Rocha PL, Branco LGS. Cardiovascular, respiratory and metabolic resposes to temperature and hypoxia of the winter frog Rana catesbeiana. Braz J Med Biol Res 1997; 30: 125-131. https://www.ncbi.nlm.nih.gov/pubmed/9222414.

40. Chapovetsky V, Katz U. Effects of season and temperature acclimation on electrocardiogram and heart rate of toads (Bufo regularis). Comp Biochem Physiol 2003; 134:77-83. https://dx.doi.org/10.1016/S10956433(02)00224-6.

41. Nagai M, Iriki M. Characteristics of cardiovascular responses of the bullfrog (Rana catesbeiana) to the thermal stimulation of the spinal cord. J Comp Physiol 1986; 156(5): 611-616. https://www.ncbi.nlm.nih.gov/pubmed/3489742.

42. Nerbonne JM, Kass RS. Molecular physiology of cardiac repolarization. Physiol Rev 2005; 85: 1205-1253. https://dx.doi.org/10.1152/physrev.00002.2005.

43. Coronel R, de Bakker JM, Wilms-Schopman FJ, Opthof T, Linnenbank $\mathrm{AC}$, Belterman $\mathrm{CN}$ et al. Monophasic action potentials and activation recovery intervals as measures of ventricular action potential duration: experimental evidence to resolve some controversies. Heart Rhythm 2006; 3: 1043-1050. https://dx.doi.org/10.1016/j.hrthm.2006.05.027.

44. Potse M, Vinet A, Opthof T, Coronel R. Validation of a simple model for the morphology of the T wave in unipolar electrograms. Am J Physiol Heart Circ Physiol 2009; 297: H792-H801. https://dx.doi.org/10.1152/ajpheart.00064.2009.
Authors:

Natalya A. Kibler - PhD, Researcher, Laboratory of Cardiac Physiology, Institute of Physiology, Komi Science Center, Urals Division of Russian Academy of Sciences, Syktyvkar, Russia. http://orcid.org/0000-0002-97757717.

Vladimir P. Nyzhny - MD, DSc, Senior Researcher, Laboratory of Cardiac Physiology, Institute of Physiology, Komi Science Center, Urals Division of Russian Academy of Sciences, Syktyvkar, Russia. http://orcid.org/00000002-5573-5499.

Dmitry N. Shmakov - MD, DSc, Chief Researcher, Laboratory of Cardiac Physiology, Institute of Physiology, Komi Science Center, Urals Division of Russian Academy of Sciences, Syktyvkar, Russia. http://orcid.org/0000$\underline{0001-7799-9236}$ 